\title{
Gravity Effect on Capillary Limit in a Miniature Loop Heat Pipe with Multiple Evaporators and Multiple Condensers
}

\author{
Hosei Nagano ${ }^{1}$, and Jentung $\mathrm{Ku}^{2}$ \\ ${ }^{1}$ JAXA/ISAS (NASA Visiting Researcher), 3-1-1 Yoshinodai, Sagamihara, Kanagawa 229-8510, Japan \\ ${ }^{2}$ NASA Goddard Space Flight Center, Greenbelt, Maryland 20771, USA
}

\begin{abstract}
This paper describes the gravity effect on heat transport characteristics in a miniature loop heat pipe with multiple evaporators and multiple condensers. Tests were conducted in three different orientations: horizontal, $45 \mathrm{deg}$ tilt, and vertical. The gravity affected the loop's natural operating temperature, the maximum heat transport capability, and the thermal conductance. In the case that temperatures of compensation chambers were actively controlled, the required control heater power was also dependent on the test configuration. In the vertical configuration, the secondary wick was not able to pump the liquid from the $\mathrm{CC}$ to the evaporator against the gravity. Thus the loop could operate stably or display some peculiar behaviors depending on the initial liquid distribution between the evaporator and the CC. Because such an initial condition was not known prior to the test, the subsequent loop performance was unpredictable.
\end{abstract}

Keywords. Ionp heat pipe, two-phase, spacecraft thermal control, multiple evaporators and condensers, gravity effect, capillary limit

\section{INTRODUCTION}

Mechanical pumped loops (single-phase) and capillary pump loops (two-phase) have been utilized as high heat transport device for spacecraft. Recently, loop heat pipes (LHPs) have gained increasing acceptance as thermal control devices for space applications because of their robustness and reliability. A typical LHP consists of an evaporator, a compensation chamber, a condenser, and liquid and vapor lines. It can transport large heat loads over long distances with small temperature gradients based on surface tension forces developed by the capillary wick. LHPs have been used on many NASA spacecrafts including ICESAT, EOS-AURA, GOES and SWIFT, and commercial communication satellites. As spacecraft become smaller, all spacecraft components, including the thermal subsystem, must be down sized. In addition, an LHP with multiple evaporators is highly desirable to accommodate multiple instruments or an instrument with a large thermal footprint [7-9].

Recently NASA Goddard Space Flight Center has developed a miniature LHP (MLHP) with the following features:

1) Two evaporators and two condensers in a single LHP

2) Two miniature evaporators with $6.35 \mathrm{~mm} O . \mathrm{D}$. wicks

3) Thermoelectric converters (TECs) for temperature control and start-up success

Comprehensive ground tests which included start-up, capillary limit, power cycle, sink temperature cycle, and their gravity dependence have been conducted in order to demonstrate stable, reliable, and repeatable operation of the MLHP. In one-G environment, the gravity affects fluid distribution inside the LHP, which in turn affects LHP operation and performance such as start-up, capillary limit and heat dissipation among condensers. To investigate the gravity effects, the MLHP was tested under three different configurations: horizontal, $45 \mathrm{deg}$ tilt, and vertical. This paper will describe the gravity effect on capillary limit of the MLHP. 


\section{TEST ARTICLE AND TEST SETUP}

The MLHP test article consists of two parallel evaporators, two parallel condensers, a common vapor transport line and a common liquid return line. Each evaporator has its own integral CC. Main features of this MLHP include 1) 9.65-mm O.D. evaporators. 2) Titanium primary wicks with $6.35 \mathrm{~mm}$ O.D. and $1.65 \mu \mathrm{m}$ pore size. 3) SS vapor and liquid transport lines with $2.38 \mathrm{~mm}$ and $1.59 \mathrm{~mm}$ O.D., respectively. 4) Aluminum condensers with $2.38 \mathrm{~mm}$ O.D. 5) A thermoelectric converter (TEC) is attached to each CC. A flow regulator made of capillary wick with 10 micron diameter is installed at the downstream of each condenser. The loop is charged with 29 grams of anhydrous ammonia. The fluid inventory in MLHP is enough to flood the entire loop with liquid under the cold condition except that one of the CCs has $10 \%$ liquid. A 400 -gram aluminum mass was attached to each evaporator to simulate the instrument mass. A cartridge heater was inserted into each thermal mass to provide heat loads between $1 \mathrm{~W}$ and $150 \mathrm{~W}$ per evaporator. Copper thermal straps connect the rear side of the TEC to the evaporators. Figure 1 shows the schematic of the test loop with thermocouple locations. Seventy-six (76) thermocouples are used to measure the loop temperatures. As shown in Figure 2, tests were conducted in three different orientations; a) horizontal, b) 45 deg tilted, and c) vertical. Figure 3 shows the photo of MLHP tilted 45 degree for testing.

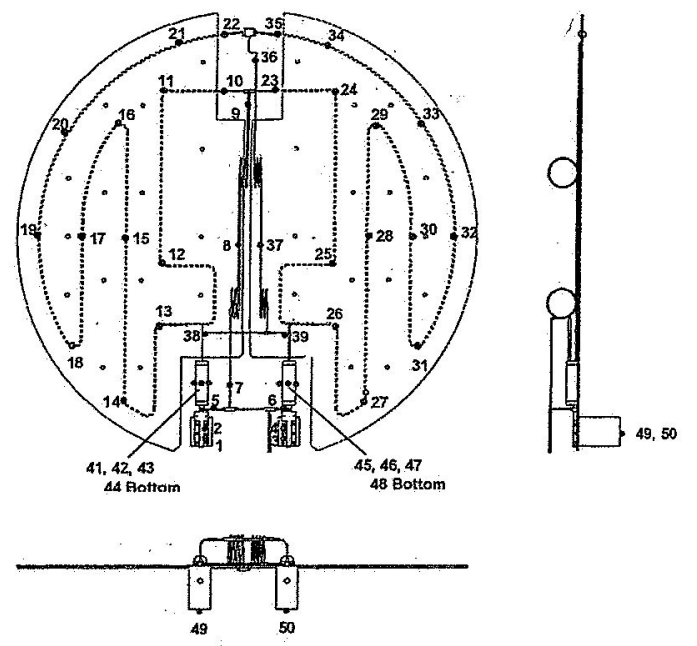

(a) Overall

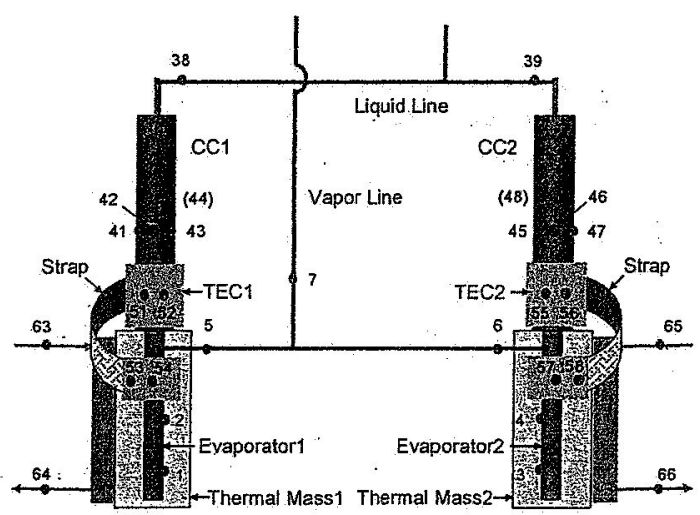

(b) Near evaporators and CCs

FIGURE 1. Thermocouple Location of MLHP (a) overall and (b) near evaporators and CCs.

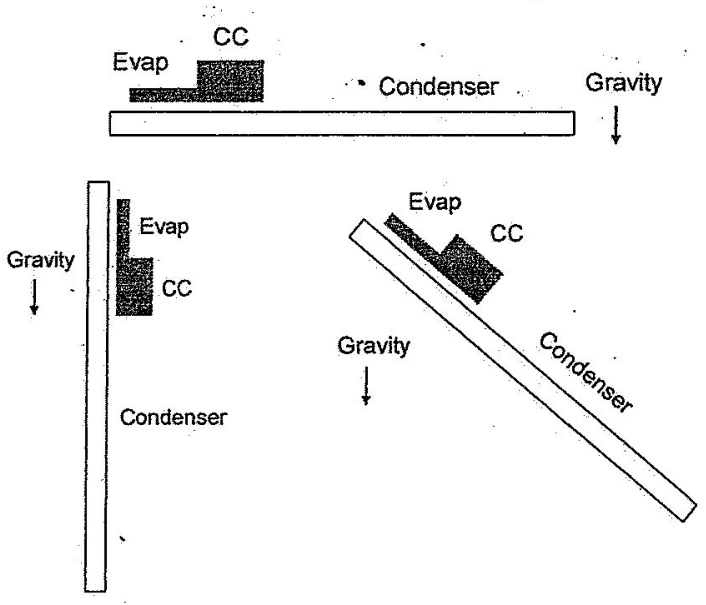

FIGURE 2. LHP orientation in the test (a). Baseline: horizontal, evaporators/CCs $100 \mathrm{~mm}$ above condensers, (b) 45- degree Tilt: E1 above $\mathrm{CC} 1, \mathrm{E} 2$ above $\mathrm{CC} 2$, and (c) Vertical: $\mathrm{E} 1$ above $\mathrm{CC} 1, \mathrm{E} 2$ above $\mathrm{CC} 2$

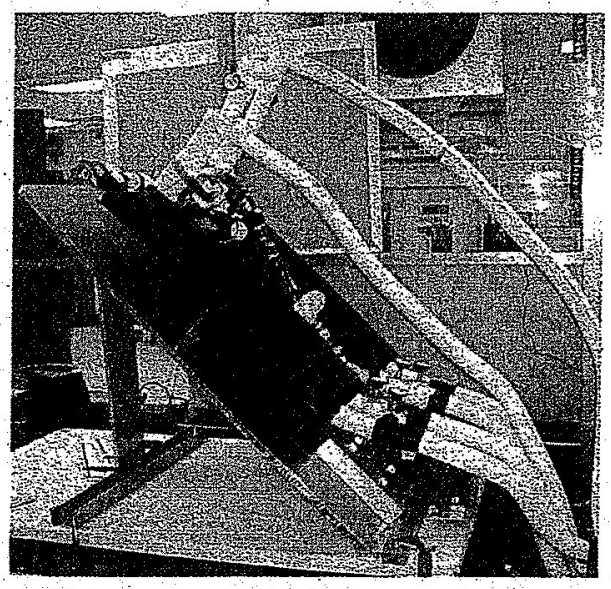

FIGURE 3. Photo of MLHP tilted 45 degree for testing. 


\section{TESTS PERFORMED}

The capillary limit of an LHP is reached when the total pressure drop in the loop, which is the sum of the pressure drops in the bayonet, primary wick, vapor grooves, vapor line, condenser, liquid line, and the gravity head, is equal to the capillary capability of the primary wick. When the capillary limit is exceeded, the vapor will penetrate the primary wick and reach the evaporator core. Because the secondary wick can transport liquid from the $\mathrm{CC}$ to the evaporator, the evaporator can tolerate the presence of vapor in its core. Therefore, even when the capillary limit is exceeded at a given operating temperature, the LHP could continue to operate at a higher operating temperature. The higher operating temperature results in a decreased surface tension and capillary pumping capability of the primary wick, but it also results in more condenser area being blocked with liquid and a smaller pressure drop in the condenser section. The frictional pressure drops in evaporator grooves and transport lines will also decrease due to decreasing vapor and liquid viscosities at the higher temperature. Thus, the loop could reach a new steady state at a higher operating temperature.

In the tests under one-G environment, the gravity will affect the LHP natural operating temperature. The natural operating temperature will increase, with an increasing adverse elevation, especially at low powers, for the following reason. As the pressure difference across the evaporator wick increases due to gravity head, the difference in saturation temperatures on both sides of the evaporator wick also increases. This leads to an increasing heat leak from the evaporator to the CC. Since the liquid enthalpy entering the $\mathrm{CC}$ does not change, the only way to compensate for the increasing heat leak is to increase the $\mathrm{CC}$ temperature. Gravity also affects the heat transport capability of an LHP, i.e. the LHP heat transport capability decreases with an increasing adverse elevation due to an additional gravity head.

In order to evaluate the gravity effect on the capillary limit of MLHP, more than 80 high power tests were conducted in horizontal, 45 deg tilt, and vertical configurations. In this paper, experimental results of 11 comparable tests, as presented in Table 1, will be discussed.

TABLE 1. High Power Tests Under Various Test Configurations

\begin{tabular}{|c|c|c|c|c|c|}
\hline Case & $\begin{array}{l}\mathrm{CC} 1 / \mathrm{CC} 2 \\
\text { Point }(\mathrm{K}) \\
\end{array}$ & \begin{tabular}{l|l} 
Set & $C 1 / C 2 \operatorname{Sin}$ \\
& Temp $(\mathrm{K})$
\end{tabular} & $\begin{array}{l}\text { Test } \\
\text { Date }\end{array}$ & Configuration & Heat Load to Evaporators (W) \\
\hline \multirow{2}{*}{1} & \multirow{2}{*}{$-/-$} & \multirow{2}{*}{$273 / 273$} & $7 / 5 / 05$ & Horizontal & E1/E2: $20 / 0,40 / 0,60 / 0,80 / 0,90 / 0,100 / 0,110 / 0,120 / 0,60 / 0$ \\
\hline & & & $9 / 6 / 05$ & Vertical & E1/E2: $5 / 0,20 / 0,40 / 0,60 / 0,80 / 0,90 / 0,95 / 0,100 / 0,5 / 0$ \\
\hline \multirow{3}{*}{2} & \multirow{3}{*}{-} & \multirow{3}{*}{$273 / 273$} & $6 / 1 / 05$ & Horizontal & $\begin{array}{l}\text { E1/E2: } 10 / 10,20 / 20,30 / 30,40 / 40,50 / 50,60 / 60,70 / 70,75 / 75 \\
80 / 80,50 / 50-\end{array}$ \\
\hline & & & $8 / 3 / 05$ & Tilt $(45 \mathrm{deg})$ & E1/E2: $10 / 10,20 / 20,40 / 40,60 / 60,70 / 70,75 / 75,80 / 80,50 / 50$ \\
\hline & & & $8 / 29 / 05$ & Vertical & $\mathrm{E} 1 / \mathrm{E} 2: 10 / 10,20 / 20,40 / 40,60 / 60,0 / 0,5 / 5$ \\
\hline \multirow{3}{*}{3} & \multirow{3}{*}{ 303/-- } & \multirow{3}{*}{$273 / 273$} & $5 / 23 / 05$ & Horizontal & E1/E2: $5 / 0,20 / 0,40 / 0,60 / 0,70 / 0,80 / 0,90 / 0,100 / 0,110 / 0,0 / 0$ \\
\hline & & & $7 / 26 / 05$ & Tilt (45 deg) & E1/E2: $5 / 0,20 / 0,60 / 0,80 / 0,90 / 0,100 / 0,110 / 0$ \\
\hline & & & $8 / 19 / 05$ & Vertical & E1/E2: $5 / 0,20 / 0,40 / 0,60 / 0,80 / 0,90 / 0,95 / 0,100 / 0,105 / 0,20 / 0$ \\
\hline \multirow{3}{*}{4} & \multirow{3}{*}{$313 / 313$} & \multirow{3}{*}{$253 / 253$} & $7 / 21 / 05$ & Horizontal & $\begin{array}{l}\text { E1/E2: } 10 / 10,20 / 20,30 / 30,40 / 40,50 / 50,60 / 60,65 / 65,70 / 70 \text {, } \\
75 / 75,80 / 80\end{array}$ \\
\hline & & & $8 / 2 / 05$ & Tilt (45 deg) & $E 1 / E 2: 20 / 20,40 / 40,60 / 60,80 / 80$ \\
\hline & & & $8 / 26 / 05$ & Vertical & $\mathrm{E} 1 / \mathrm{E} 2: 5 / 5,20 / 20,40 / 40,60 / 60,80 / 80,20 / 20,10 / 10,0 / 10,10 / 10$ \\
\hline
\end{tabular}

\section{TEST RESULTS}

Overall, the horizontal configuration yielded the highest heat load before the loop reached its capillary limit for a given condenser sink temperature. The maximum heat load at the capillary limit decreased as the tilt angle increased. Also, the CC saturation temperature increased as the tilt angle increased, that is, the temperature in the vertical configuration is the highest and that in the horizontal configuration is the lowest. When the CC temperatures were actively controlled using TECs, the required TEC control heater power was the largest in the horizontal configuration. Furthermore, in the horizontal configuration, the loop could recover from a dry-out condition after the capillary limit was exceeded by simply reducing the heat load to the evaporators. In the vertical configuration, however, the loop could not recover from a dry-out in most cases once the capillary limit was exceeded. 


\section{No Active Control of CC Temperatures}

Figure 4 shows the loop temperatures in the test case 1 where the heat load was applied to E1 only under the horizontal configuration. Since E2 received no heat load, E2 worked as a condenser and CC2 controlled the loop operating temperature until the loop reached its capillary limit. The capillary limit of E1 was exceeded at 100W/0W as evidenced by four accompanying events: 1) The $\mathrm{CCl}$ temperatures exceeded the $\mathrm{CC} 2$ temperatures, which suggested that vapor had penetrated through the E1 wick and CC1 began to control the loop operating temperature. 2) Following the vapor penetration, cold liquid was pushed from TC38 to TC39 along the liquid line, causing E2 inlet temperature TC39 to drop temporarily. 3) The $\mathrm{CC} 1$ temperature increased rapidly for a modest power increase. 4) The temperature difference between $\mathrm{E} 1$ and $\mathrm{CC} 1$ also increased rapidly for a modest power increase due to a decreasing thermal conductance after the vapor penetration. Nevertheless, the loop continued to function at a higher operating temperature. The loop also approached another steady temperature as the heat load further increased to $110 \mathrm{~W} / 0 \mathrm{~W}$. The loop completely recovered as the heat load was reduced to $60 \mathrm{~W} / 0 \mathrm{~W}$. However, the $\mathrm{CC} 1$ temperature was about $10 \mathrm{~K}$ higher than that at $60 \mathrm{~W} / 0 \mathrm{~W}$ prior to the vapor penetration, indicating a residual effect from an earlier vapor penetration.

Figure 5 illustrates the loop temperatures in the vertical configuration where the heat load was applied to E1 only. At low powers, $\mathrm{CC} 1$ controlled the loop operating temperature. At heat load of $60 \mathrm{~W} / 0 \mathrm{~W}, \mathrm{CC} 2$ began to control the loop operating temperature. Above $80 \mathrm{~W} / 0 \mathrm{~W}$, operating temperature control was switched from $\mathrm{CC} 2$ to $\mathrm{CC} 1$ again, and E1 temperature rose rapidly, indicating that $\mathrm{E} 1 \mathrm{had}$ reached its capillary limit. The loop could operate steadily at a higher saturation temperature with $90 \mathrm{~W} / 0 \mathrm{~W}$. At $100 \mathrm{~W} / 0 \mathrm{~W}, \mathrm{El}$ temperature sudden rose and began a temperature excursion. When the heat load was reduced to $5 \mathrm{~W} / 0 \mathrm{~W}$, the loop recovered from a dry-out. However, the $\mathrm{CCl}$ and $\mathrm{CC} 2$ temperatures were a few degrees higher than that at $5 \mathrm{~W} / 0 \mathrm{~W}$ prior to the vapor penetration.

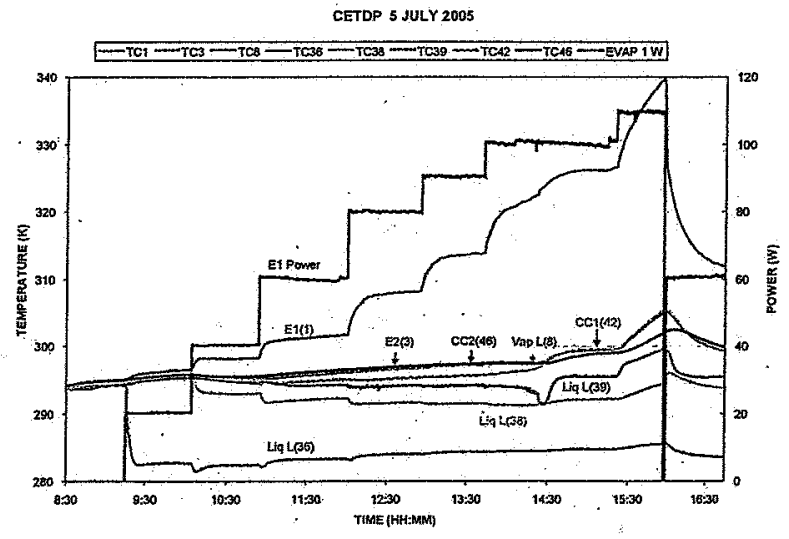

FIGURE 4. Loop Temperatures with Heat Load to E1 Only in Horizontal Configuration

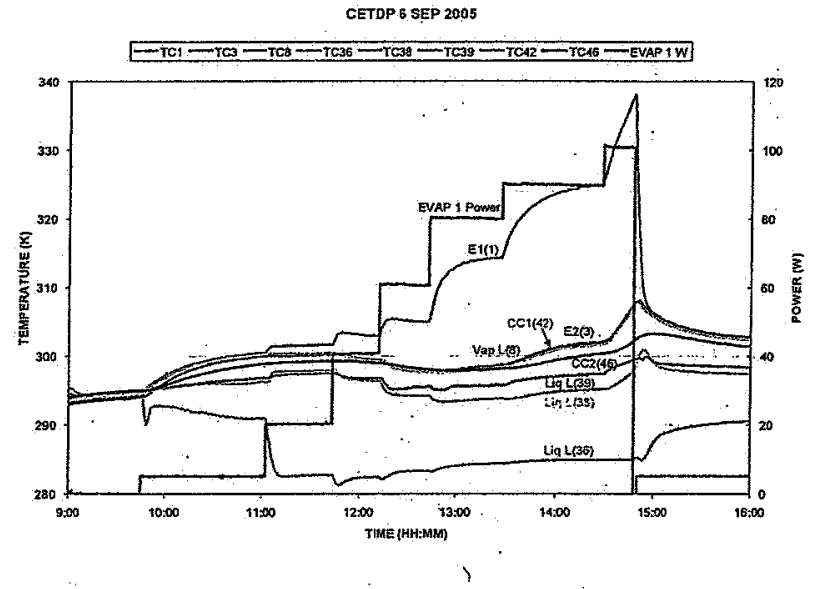

FIGURE 5. Loop Temperatures with Heat Load to El Only in Vertical Configuration

Figure 6 shows the comparison of the evaporator temperatures and the loop saturation temperature as a function of the applied power in horizontal and vertical configurations. The loop saturation temperature was determined by the higher of the two CC temperatures. The evaporator temperature and the loop saturation temperature were higher under the vertical configuration than under the horizontal configuration at all heat loads. For example, the evaporator temperature and the saturation temperature in the horizontal configuration at $90 \mathrm{~W} / 0 \mathrm{~W}$ were about $11 \mathrm{~K}$ and $2 \mathrm{~K}$ lower than those in the vertical configuration, respectively. In addition, the heat transport capability under the vertical configuration was about $10 \mathrm{~W}$ lower than under the horizontal configuration. Figure 7 shows the calculated of thermal conductance. The thermal conductance was calculated from the applied power, evaporator temperature, and saturation temperature as follows; 


$$
G_{C O N D, i}=Q_{L O A D, i} /\left(T_{E V A, i}-T_{S A T}\right)(i=1,2)
$$

The thermal conductance decrease as the applied power increased. Thermal conductance in vertical configuration was always lower than that in horizontal configuration, and that difference was higher at lower powers.

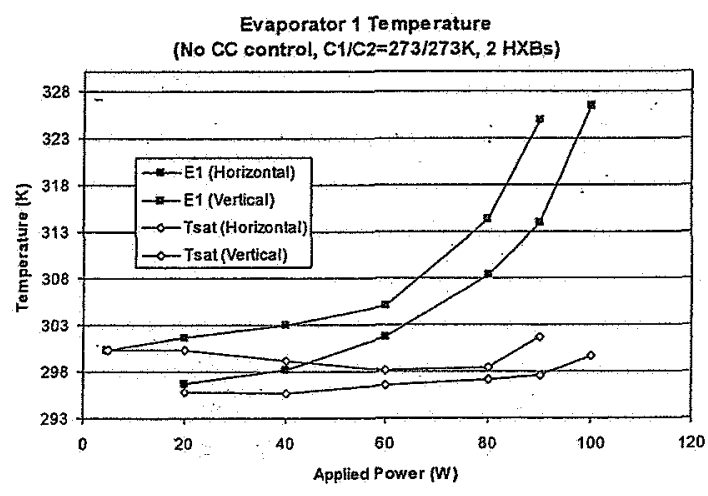

FIGURE 6. Evaporator and Saturation Temperature as a Function of Applied Power

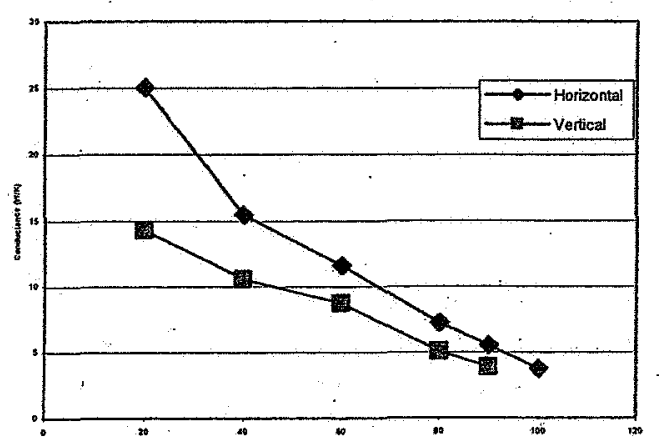

FIGURE 7. Thermal conductance of the Loop as a Function of Applied Power

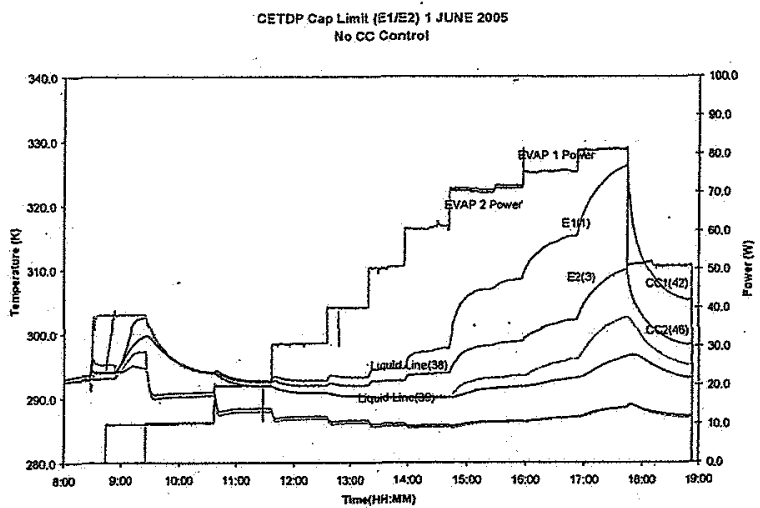

FIGURE 8. Loop Temperatures with Heat Load to Both Evaporators in Horizontal Configuration

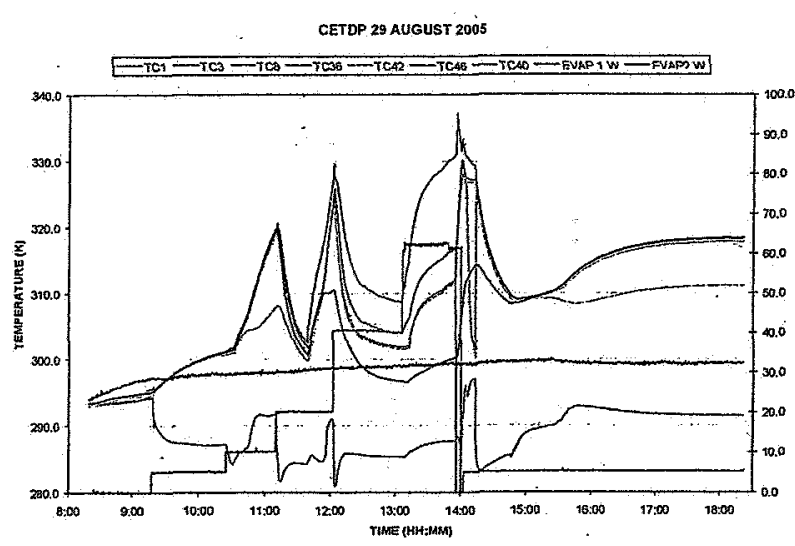

FIGURE 9. Loop Temperatures with Heat Load to Both Evaporators in Vertical Configuration

In the test case 1 , the test result in vertical configuration showed similar behavior with that in horizontal, although the loop saturation temperature and the evaporator temperature were higher at a given heat load. In the test case 2 , however, the loop behavior in vertical showed different phenomena from horizontal and $45 \mathrm{deg}$ tilted configurations as will be discussed next. In the vertical configuration, the secondary wick was not able to pump the liquid against gravity from the CC at the bottom to the evaporator at the top. Test results indicate that in some cases the loop could operate steady as the heat load was increased gradually in steps. In other cases, the loop could deprime at any given heat load unexpectedly. It is postulated that the initial fluid distribution in the evaporator core was a major factor affecting the subsequent loop performance. Because the initial condition was not known, the loop could yield rather unpredictable behavior under the vertical configuration. 
Figure 8 shows the loop temperatures in the test case 2 where an even heat load was applied to both evaporators in the horizontal configuration. The E1 temperature was always higher than E2 temperature. This was most likely due to a manufacturing issue that resulted in a lower thermal conductance in E1. The evaporator temperatures began to rise rapidly at $70 \mathrm{~W} / 70 \mathrm{~W}$ for a modest power increase. The $\mathrm{CC} 1$ temperature also rose and began to control the loop operating temperature. After capillary limit was exceeded at the given operating temperature, however, the loop continued to operate steadily at higher operating temperatures with $75 \mathrm{~W} / 75 \mathrm{~W}$ and $80 \mathrm{~W} / 80 \mathrm{~W}$. When the heat load was reduced to $50 \mathrm{~W} / 50 \mathrm{~W}$, the loop recovered from a dry-out. However, the $\mathrm{CC} 1$ and $\mathrm{CC} 2$ temperatures were higher than that at $50 \mathrm{~W} / 50 \mathrm{~W}$ prior to the vapor penetration, indicating a residual effect from an earlier vapor penetration.

Figure 9 shows the loop temperatures in the vertical configuration. The loop started with a heat load of $5 \mathrm{~W} / 5 \mathrm{~W}$. When the power increased to $10 \mathrm{~W} / 10 \mathrm{~W}$, however, the evaporator and $\mathrm{CC}$ temperatures rose rapidly, indicating a possible dry-out. The heat load was increased to $20 \mathrm{~W} / 20 \mathrm{~W}$, and the $\mathrm{CC}$ and evaporator temperatures temporarily. About 30 minutes later, however, the loop temperatures rose again. As the heat load was increased to $40 \mathrm{~W} / 40 \mathrm{~W}$, the same phenomena repeated. At the heat load of $60 \mathrm{~W} / 60 \mathrm{~W}$, the $C C$ and evaporator temperatures continued to rise. After that the power was reduced to $5 \mathrm{~W} / 5 \mathrm{~W}$, and the loop recovered. However, the overall temperatures in steady state were higher than previous values at $5 \mathrm{~W} / 5 \mathrm{~W}$. This was one of the four cases where the loop displayed unpredictable behaviors under the vertical configuration. In eleven other cases, the loop operated steadily as the heat load was increased in steps. Furthermore, one test might show strange phenomenon while another test conducted in a different day would show normal operation under the seemingly identical start-up power and sink temperatures.

Figure 10 illustrates the temperature of the E1/E2 and loop saturation temperature in the test case 2. It was clearly seen that the steady state temperature of the evaporators and saturation temperature were higher as the elevation of the evaporator increased. Figure 11 shows the evaporator thermal conductance as a function of the heat load under various test configurations. The thermal conductance decreased with an increasing load increased and/or an increasing tilt angle.

(No $\mathrm{CC}$ control, $\mathrm{C} / \mathrm{C} 2=273 / 273 \mathrm{~K}$ )

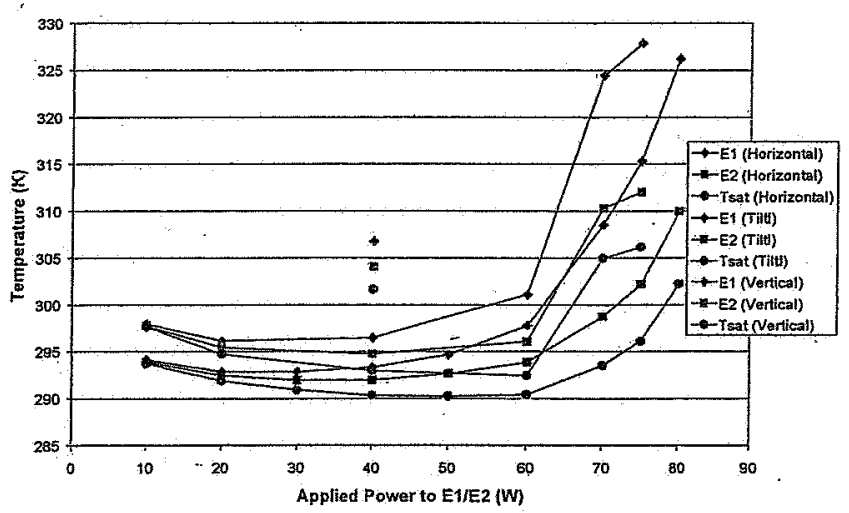

FIGURE 10. Evaporator and Saturation Temperature as a Function of Heat Load Under Various Test Configurations

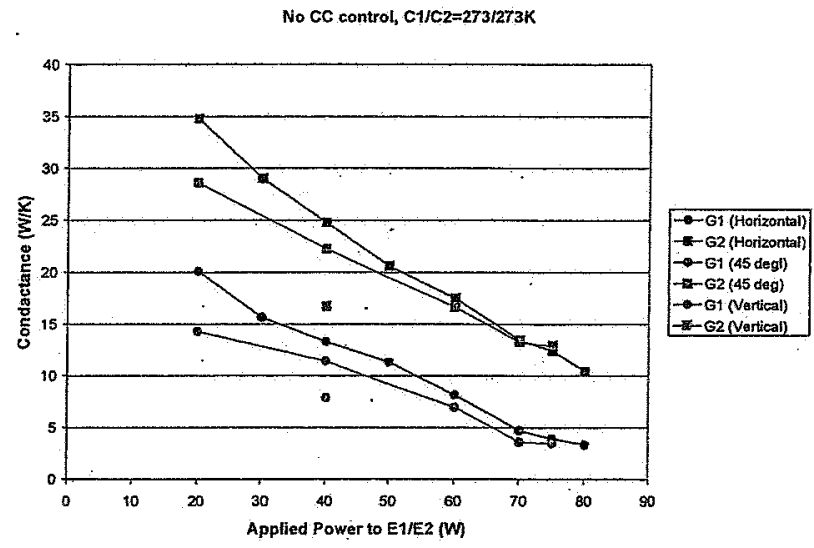

FIGURE 11. Evaporator Thermal Conductance as a Function of Heat Load Under Various Test Configurations

\section{Active Control of CC Temperatures}

In the test case 3 where the CC temperatures were actively controlled by the TECs, the CC temperatures could be controlled at $303 \mathrm{~K}$ throughout the test. Figure 12 shows the evaporator temperature in each configuration as a function of the heat load in test case 3. The evaporators and CC saturation temperatures under the steady state got higher as the tilt angle increased. Figure 13 shows the TEC power required to maintain the CC temperature at $303 \mathrm{~K}$ in each configuration. Until the loop reached its capillary. limit, the CCS could be controlled at $303 \mathrm{~K}$ by using TECs. The required TEC power in horizontal condition was larger than those under the other two configurations. The results were consistent with the fact that the natural operating temperatures under the $45 \mathrm{deg}$ tilt and vertical configurations were higher than that under the horizontal configuration. 


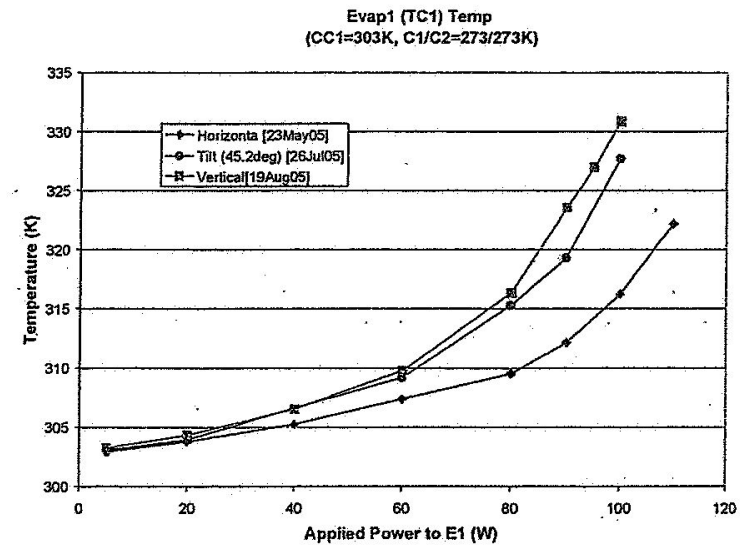

FIGURE 12. Evaporator Temperature as a Function of Heat Load Under Various Test Configurations

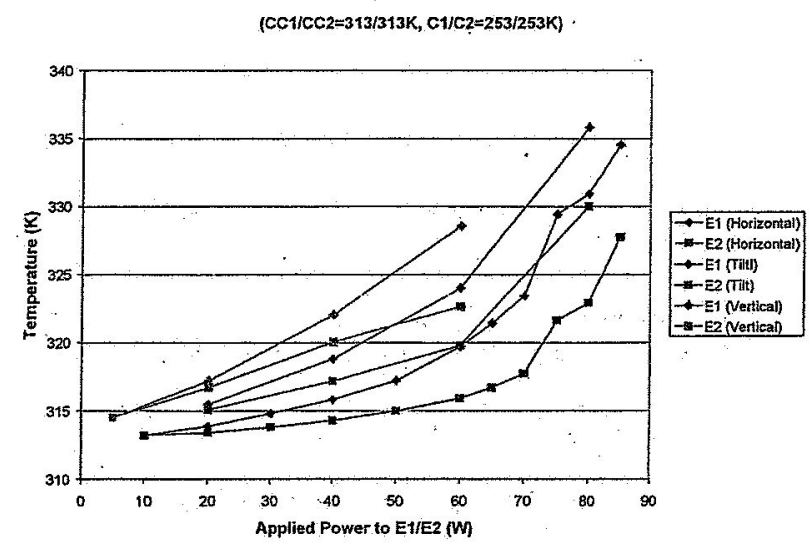

FIGURE 14. Evaporator Temperature as a Function of Heat Load Under Various Test Configurations

In the test case 4 , the $\mathrm{CC}$ temperatures could be controlled at $313 \mathrm{~K}$ in each test configuration until the loop exceeded its capillary limit. Figure 14 shows the evaporator temperature in each configuration as a function of applied power in test case 4 . The maximum powers at the capillary limit under the horizontal, 45 deg tilted, and vertical configurations were $85 \mathrm{~W} / 85 \mathrm{~W}, 80 \mathrm{~W} / 80 \mathrm{~W}$, and $60 \mathrm{~W} / 60 \mathrm{~W}$, respectively. The $\mathrm{E} 1 / \mathrm{E} 2$ temperatures at $60 \mathrm{~W} / 60 \mathrm{~W}$ in $45 \mathrm{deg}$ tilt and vertical configurations were $5 \mathrm{~K}$ and $10 \mathrm{~K}$ higher than that in the horizontal configuration, respectively. Figure 15 shows the TEC power to maintain the loop operating temperature at $313 \mathrm{~K}$. The required TEC power in the horizontal configuration was $0.1-0.5 \mathrm{~W}$ lower than those in the $45 \mathrm{deg}$ tilt and vertical configurations, respectively.

Figure 16 illustrates the loop temperatures of test case 4 in the vertical configuration. The heat load ranged from $5 \mathrm{~W} / 5 \mathrm{~W}$ to $60 \mathrm{~W} / 60 \mathrm{~W}$. When a heat load of $80 \mathrm{~W} / 80 \mathrm{~W}$ was applied, E 1 temperature rose rapidly and reached the capillary limit. The loop could not recover from a dry-out

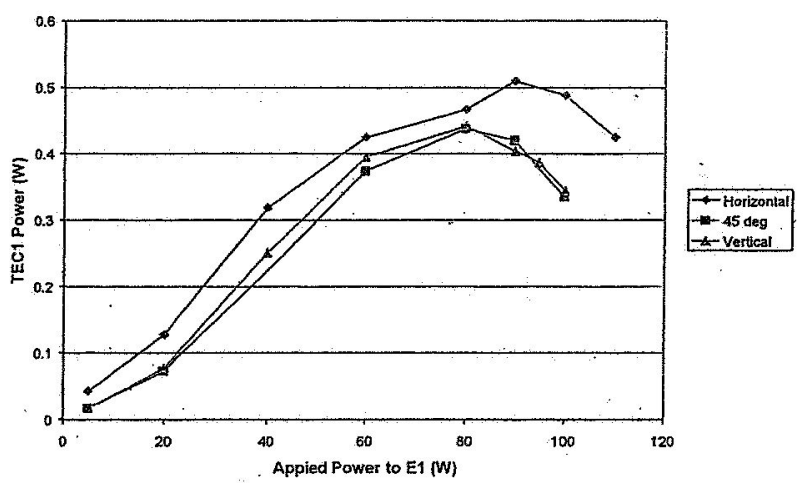

FIGURE 13. TEC power as a function of Heat Load Under Various Test Configurations

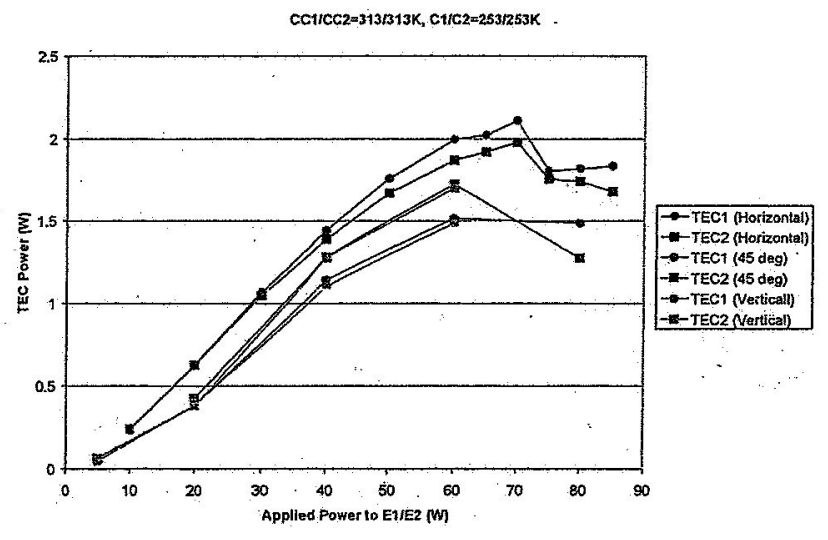

FIGURE 15. TEC Power as a Function of Heat Load Under Various Test Configurations

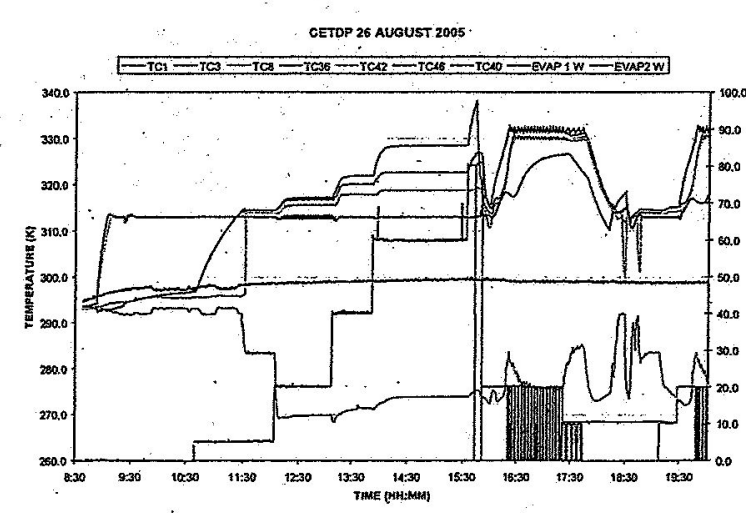

FIGURE 16. Loop Temperatures with Heat Load to Both Evaporators and $\mathrm{CC}$ Active Control in Vertical Configuration 
when the power was reduced to $20 \mathrm{~W} / 20 \mathrm{~W}$. After that, the power was reduced to $10 \mathrm{~W} / 10 \mathrm{~W}$, and then the loop recovered. When power increased to $20 \mathrm{~W} / 20 \mathrm{~W}$ again, the loop deprimed. The loop could start successfully after being left un-powered overnight to allow the re-priming of the wicks.

\section{CONCLUSIONS}

The gravity effect on the capillary limit of a miniature LHP with two evaporators and two condensers were experimentally evaluated. The following results were obtained.

(1) When CC temperatures were not actively controlled, the gravity affected the LHP natural operating temperature. The natural operating temperature increased with an increasing adverse elevation. Gravity also affects the LHP heat transport capability, i.e. the heat transport capability decreased with an increasing adverse elevation due to an additional gravity head.

(2) When the CC temperatures were controlled using TECs, the loop operating temperature was controlled throughout the test. The required TEC power in horizontal configuration was larger than those under the in $45 \mathrm{deg}$ tilt and vertical configurations. The result was consistent with the fact that the loop's natural operating temperature was higher under the horizontal configuration.

(3) Under the vertical configuration, the loop could operate stably or display unpredictable behaviors even under seemingly identical test conditions. It is postulated that the initial fluid distribution in the secondary wick and the evaporator core led to subsequent different loop behaviors.

\section{REFERENCES}

1. Ku, J. and G. Birur, "Active Control of the Operating Temperature in a Loop Heat Pipe with Two Evaporators and Two Condensers," 31 st International Conference on Environmental Systems (ICES), Society of Automotive Engineers, Paper No. 2001-01-2188, 2001.

2. Cheung, M., Hoang, T., Ku, J., and Kaya, T., "Thermal Performance and Operational Characteristics of Loop Heat Pipe (NRL LHP), " SAE Paper No. 981813, 28th International Conference on Environmental Systems, July13-16, 1998, Danvers, Massachusetts.

3. $\mathrm{Ku}, \mathrm{J}$., Jeong, S., and Butler, D., "Testing of a Miniture Loop Heat Pipe Using a Thermal Electrical Cooler for Temperature Control," SAE 2004-01-2505.

4. Yun, S. J., Wolf, D.., and Kroliczek, E., "Design and Test Results of Multi-Evaporator Loop Heat Pipes,". 29th International Conference on Environmental Systems (ICES), Society of Automotive Engineers, Paper No. 1999-01-2051, 1999.

5. Ku, J. and G. Birur, "Testing of a Loop Heat Pipe with Two Evaporators and Two Condensers," 31st International Conference on Environmental Systems (ICES), Society of Automotive Engineers, Paper No. 2001-01-2190, 2001.

6. Pauken, M. T., Birur, G., Nikitkin, M., and Al-Khabbaz, F., "Thermal Performancé Evaluation of a Small Loop Heat Pipe for Space Applications," 33rd International Conference on Environmental Systems (ICES), Society of Automotive Engineers, Paper No. 2003-01-2688, 2003.

7. Ku, J., "Operating Characteristics of Loop Heat Pipes," SAE Paper No. 1999-01-2007, 1999.

8. Ku, J., and Birur, G., "Capillary limit in a Loop Heat Pipe with Dual Evaporators," 32nd International Conference on Environmental Systems (ICES), Society of Automotive Engineers, Paper No. 2002-01-2503, 2002.

9. Donatas Mishkinis, Guanghan Wang, Darius Nikanpour, Erin MacDonald and Tarik Kaya, "Ädvances in Two-Phase Loop with Capillary Pump Technology and Space Applications," 2005-01-2883, 2005.

(Under witing) 


\section{APPENDIX}

Maximum applicable power, Evaporator and saturation temperature, and TEC power in the test.

TABLE A-1. Test Result of the Case1

\begin{tabular}{|l|l|l|}
\hline \multirow{2}{*}{ Condition } & \multicolumn{2}{|l|}{$\begin{array}{l}\text { No CC temperature control } \\
\text { Power to E1 only } \\
\text { C1/C2=273K/273K }\end{array}$} \\
\hline Configuration & Horizontal & Vertical \\
\hline Date & $7 / 5 / 05$ & $9 / 6 / 05$ \\
\hline Max Q & $100 / 0$ & $90 / 0$ \\
\hline E1Temp (90W/OW) & 313.8 & 324.9 \\
\hline Tsat Temp(90W/0W) & 299.6 & 301.7 \\
\hline
\end{tabular}

TABLE A-2. Test Result of the Case2

\begin{tabular}{|l|l|l|l|}
\hline \multirow{2}{*}{$\begin{array}{l}\text { Condition } \\
\end{array}$} & \multicolumn{3}{l}{$\begin{array}{l}\text { No CC temperature control } \\
\text { Power to E1 and E2 } \\
\text { C1/C2=273K/273K }\end{array}$} \\
\hline Configuration & Horizontal & Tilt 45 deg & Vertical \\
\hline Date & $6 / 1 / 2005$ & $8 / 3 / 2005$ & $8 / 29 / 2005$ \\
\hline Max Q & $80 / 80$ & $75 / 75$ & $40 / 40$ \\
\hline E1Temp $(75 \mathrm{~W} / 75 \mathrm{~W})$ & 315.2 & 327.8 & - \\
\hline E2Temp(75W/75W) & 302.2 & 312.0 & - \\
\hline Tsat Temp(75W/75W) & 296.1 & 306.2 & - \\
\hline
\end{tabular}

TABLE A-3. Test Result of the Case3

\begin{tabular}{|l|l|l|l|}
\hline \multirow{2}{*}{ Condition } & \multicolumn{2}{l|}{$\begin{array}{l}\text { CC1/CC2 }=303 \mathrm{~K} / \mathrm{NC} \\
\text { Power to E1 only } \\
\text { C1/C2=273K/273K }\end{array}$} \\
\hline Configuration & Horizontal & Tilt 45 deg & Vertical \\
\hline Date & $5 / 23 / 2005$ & $7 / 26 / 2005$ & $8 / 19 / 2005$ \\
\hline Max Q(W) & $110 / 0$ & $100 / 0$ & $100 / 0$ \\
\hline E1Temp $(100 \mathrm{~W} / 0 \mathrm{~W})$ & 316.2 & 327.7 & 330.8 \\
\hline TEC pow $(0 \mathrm{~W} / 100 \mathrm{~W})$ & 0.48 & 0.33 & 0.34 \\
\hline
\end{tabular}

TABLE A-4. Test Result of the Case4

\begin{tabular}{|l|l|l|l|}
\hline Condition & \multicolumn{4}{l|}{$\begin{array}{l}\text { CC1/CC2=313K/313K } \\
\text { Power to E1 and E2 } \\
\text { C1/C2=253K/253K }\end{array}$} \\
\hline Configuration & Horizontal & Tilt 45 deg & Vertical \\
\hline Date & $7 / 21 / 2005$ & $8 / 2 / 2005$ & $8 / 26 / 2005$ \\
\hline Max Q & $85 / 85$ & $80 / 80$ & $60 / 60$ \\
\hline E1Temp(60W/60W) & 319.7 & 324.0 & 328.5 \\
\hline E2Temp(60W/60W) & 315.9 & 319.8 & 322.6 \\
\hline TEC1 pow(60W/60W) & 1.99 & 1.51 & 1.48 \\
\hline TEC2 pow(60W/60W) & 1.86 & 1.72 & 1.69 \\
\hline
\end{tabular}

